Article

\title{
Fabrication of a Micromachined Capacitive Switch Using the CMOS-MEMS Technology
}

\author{
Cheng-Yang Lin ${ }^{1}$, Cheng-Chih Hsu ${ }^{2}$ and Ching-Liang Dai ${ }^{1, *}$ \\ Received: 29 August 2015 ; Accepted: 26 October 2015 ; Published: 2 November 2015 \\ Academic Editor: Miko Elwenspoek \\ 1 Department of Mechanical Engineering, National Chung Hsing University, Taichung 402, Taiwan; \\ willy06101024@yahoo.com.tw \\ 2 Department of Photonics Engineering, Yuan Ze University, Taoyuan 320, Taiwan; \\ cchsu@saturn.yzu.edu.tw \\ * Correspondence: cldai@dragon.nchu.edu.tw; Tel.: +886-4-2284-0433; Fax: +886-4-2287-7170
}

\begin{abstract}
The study investigates the design and fabrication of a micromachined radio frequency (RF) capacitive switch using the complementary metal oxide semiconductor-microelectromechanical system (CMOS-MEMS) technology. The structure of the micromachined switch is composed of a membrane, eight springs, four inductors, and coplanar waveguide (CPW) lines. In order to reduce the actuation voltage of the switch, the springs are designed as low stiffness. The finite element method (FEM) software CoventorWare is used to simulate the actuation voltage and displacement of the switch. The micromachined switch needs a post-CMOS process to release the springs and membrane. A wet etching is employed to etch the sacrificial silicon dioxide layer, and to release the membrane and springs of the switch. Experiments show that the pull-in voltage of the switch is $12 \mathrm{~V}$. The switch has an insertion loss of $0.8 \mathrm{~dB}$ at $36 \mathrm{GHz}$ and an isolation of $19 \mathrm{~dB}$ at $36 \mathrm{GHz}$.
\end{abstract}

Keywords: micromachined switches; CMOS-MEMS; radio frequency

\section{Introduction}

Micromachined radio frequency (RF) switches have excellent isolation, low insertion loss, and high linearity at microwave frequencies [1,2], and they can be applied in wireless communication systems [3]. Many micromachined RF switches have been manufactured using microelectromechanical system (MEMS) technology. For instance, Wang et al. [4] used MEMS technology to fabricate a RF switch. To enhance the electrical properties of the switch, the silicon on glass (SOG) based microwave transmission line was designed, and an electroplated gold layer was deposited to the SOG process. The measured pull-in voltage of the switch was $15 \mathrm{~V}$. The measured insertion loss and isolation of the switch at $6 \mathrm{GHz}$ were 0.77 and $53 \mathrm{~dB}$, respectively. Angira et al. [5] designed a low insertion loss capacitive RF MEMS switch. To reduce the insertion loss of the RF switch, a float metal was employed to reduce the capacitance in up-state of the switch. The results showed that the RF switch had an insertion loss of $0.11 \mathrm{~dB}$ at $25 \mathrm{GHz}$ and an isolation of $52 \mathrm{~dB}$ at $10 \mathrm{GHz}$. The pull-in voltage of the switch was $12.75 \mathrm{~V}$. Gao et al. [6] manufactured an in-plane electrostatic comb-drive switch using MEMS technology. To decrease the pull-in voltage of the switch, the switch was designed as a structure of double-tilt comb fingers and tilted parallelogram beams. The measured results showed that the pull-in voltage of the switch was about $18 \mathrm{~V}$. Giffney et al. [7] developed a piezoelectrically actuated capacitive RF MEMS switch that was continuously variable between the "on" state and the "off" state. The switch was based on variable capacitance using a cantilever fixed at both ends, which was actuated by a lead zirconate titanate thin film. The actuation voltage of the switch was $22.4 \mathrm{~V}$. The insertion loss of the switch was $0.7 \mathrm{~dB}$ at $14 \mathrm{GHz}$, and the isolation of the switch was $10 \mathrm{~dB}$ at $14 \mathrm{GHz}$. Yang et al. [8] proposed a RF MEMS capacitive 
switch with low sensitivity to both in-plane stress and stress gradients. The switch contained four cantilever beams that were tired together at the center joint to minimize the effects of biaxial stress and stress gradients. Experiments showed that the pull-in voltage of the switch was about $40 \mathrm{~V}$. The insertion loss of the switch was about $1 \mathrm{~dB}$ at $20 \mathrm{GHz}$, and its isolation was about $12 \mathrm{~dB}$ at $20 \mathrm{GHz}$. Park et al. [9] made a RF MEMS switch using the sacrificial bulk micromachining process. The switch was a capacitive shunt type, which is actuated by comb-drive actuators. The measured results showed that the RF switch had an isolation of $30.1 \mathrm{~dB}$ at $24 \mathrm{GHz}$ and an insertion loss of $0.29 \mathrm{~dB}$ at $24 \mathrm{GHz}$. The measured pull-in voltage of the switch was $25 \mathrm{~V}$. Zheng et al. [10] utilized the surface micromachining process to fabricate an RF MEMS membrane switch on a GaAs substrate. The MEMS switch consisted of a membrane of $\mathrm{Au}$, a dielectric layer of $\mathrm{SiN}$, and coplanar waveguide $(\mathrm{CPW})$ lines of $\mathrm{AuGeNi} / \mathrm{Au}$. The measured pull-in voltage of the RF switch was $17 \mathrm{~V}$. The isolation of the RF switch was $42 \mathrm{~dB}$ at $24.5 \mathrm{GHz}$, and its insertion loss was $0.25 \mathrm{~dB}$ at $25.6 \mathrm{GHz}$. The bias voltage of microelectronic devices is usually 5 or $12 \mathrm{~V}$. The pull-in voltage of these RF switches [4,6-10] was between 15 to $40 \mathrm{~V}$, so they needed an extra power source and increased power consumption. In this work, we employ complementary metal oxide semiconductor (CMOS)-MEMS technology to fabricate a micromachined RF switch with low actuation voltage of $12 \mathrm{~V}$, and its pull-in voltage is lower than that of Wang et al. [4], Angira et al. [5], Gao et al. [6], Giffney et al. [7], Yang et al. [8], Park et al. [9] and Zheng et al. [10].

The use of commercial CMOS process to fabricate MEMS devices is called CMOS-MEMS technology [11-14]. Micro sensors and actuators manufactured by this technology usually require a post-CMOS process to add functional materials [15-17] or to release suspended structures [18-20]. In this work, we develop a micromachined RF switch using the CMOS-MEMS technology. The switch is a capacitive shunt type actuated by the electrostatic force. The structure of the RF switch consists of a membrane, four inductors, eight springs, and CPW lines. The Agilent Advanced Design System (ADS) is used to analyze the electrical properties of the switch. The finite element method (FEM) software CoventorWare (Coventor, Inc., Cary, NC, USA) is utilized to simulate the actuation voltage and displacement of the switch. The switch requires a post-process to release the membrane and springs. The post-process employs a wet etching to etch the sacrificial silicon dioxide layer, and to obtain the suspended structures of the switch.

\section{Structure of the Micromachined Switch}

Figure 1 illustrates the structure of the micromachined RF capacitive switch. The switch consists of a membrane, four inductors, eight springs, CPW transmission lines, and anchors. The springs support the membrane and connect to the anchors. To enhance the electrical characteristics of the switch, the inductors are adopted. The CPW transmission lines, which contain ground (G), signal (S) and ground $(\mathrm{G})$ lines, locate under the membrane. The signal line is $35 \mu \mathrm{m}$ wide and $0.53 \mu \mathrm{m}$ thick, and the ground lines are $12 \mu \mathrm{m}$ wide and $0.53 \mu \mathrm{m}$ thick. The space between the signal and ground lines is $3.3 \mu \mathrm{m}$. The width of membrane over the signal line is $38 \mu \mathrm{m}$. The micromachined switch is a capacitive shunt type that is actuated by the electrostatic actuators. As shown in Figure 1, the electrostatic actuators locate on both sides of the membrane. Each actuator is $250 \mu \mathrm{m}$ long and $60 \mu \mathrm{m}$ wide. When applying an actuation voltage to the actuators, they produce an electrostatic force to drive the membrane, resulting in the membrane stays in the down position. The RF propagation in the signal line is coupled to the ground lines of CPW, and the switch is at the "off" state. The membrane of the switch stays in the up position when there is no actuation voltage. The RF signal propagates in the signal line, and the switch is at the "on" state. Figure 2a shows the dimensions of the spring. Figure $2 \mathrm{~b}$ shows the dimensions of the inductor. All of the springs and inductors have the same dimensions. The insertion loss and isolation are important electrical characteristics of the switch, and they depend on the ratio of capacitance in the switch at the "on" and "off" states. The capacitance of switch is proportional to the area of membrane. The width of membrane, $38 \mu \mathrm{m}$, is 
larger than the width of signal line, so that the capacitance of the switch increases and the electrical characteristics enhance.

The actuation voltage of the micromachined switch depends on the stiffness of springs. In order to obtain a lower actuation voltage, the springs of the switch are designed as low stiffness. As shown in Figure 2a, each spring is $150 \mu \mathrm{m}$ long, $4 \mu \mathrm{m}$ wide and $1 \mu \mathrm{m}$ thick. The thickness of actuation plate and membrane are $1 \mu \mathrm{m}$. The actuation voltage and displacement of the switch was simulated using the FEM software CoventorWare. The model of the switch is established in accordance with the structure and dimensions as shown in Figure 1. The switch model is meshed by triangular elements. The switch material is aluminum. The material properties of aluminum are Young's modulus, 70 GPa; Poisson's ratio, 0.3; mass density, $2679 \mathrm{~kg} / \mathrm{m}^{3}$ [21,22]. Figure 3 depicts the relation between the membrane displacement and actuation voltage for the switch. The space between the membrane and the CPW lines is $3 \mu \mathrm{m}$. In this simulation, the actuation voltage changes from 0 to $13 \mathrm{~V}$. The membrane displacement of the switch is $3 \mu \mathrm{m}$ when applying an actuation voltage of $12.5 \mathrm{~V}$. Therefore, the simulated pull-in voltage of the switch is $12.5 \mathrm{~V}$. The CoventorWare was also used to evaluate the resonant frequency of the micromachined switch. The results depicted that the first resonant frequency of the switch was $24 \mathrm{kHz}$.

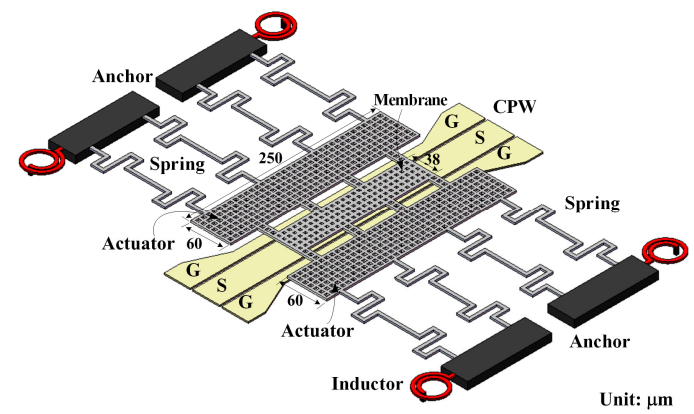

Figure 1. Structure of the micromachined switch. CPW: Coplanar waveguide; G: Ground; S: Signal.

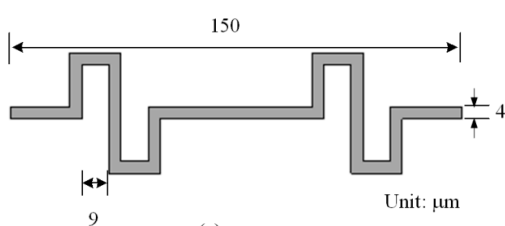

(a)

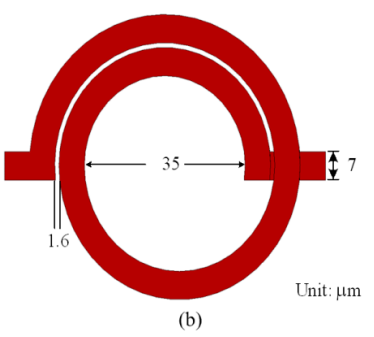

(b)

Figure 2. Dimensions of (a) spring; and (b) inductor.

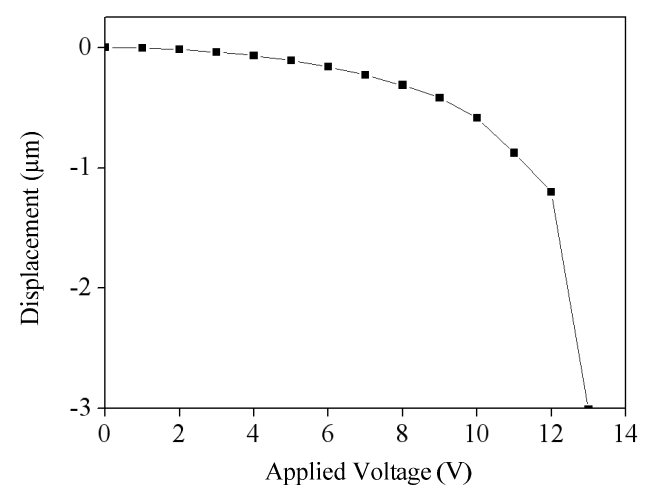

Figure 3. Relation between membrane displacement and actuation voltage for the switch. 
Figure 4 shows the stress distribution of the switch with an actuation voltage of $12.5 \mathrm{~V}$. The simulation results depict that the anchored end of the springs has a maximum von Mises stress of $14 \mathrm{MPa}$. The deformation of the switch operates in the elastic range because the maximum stress of the switch is below the aluminum yield strength of $124 \mathrm{MPa}$.

The Agilent computer-aided design (CAD) tool was employed to analyze the characteristic impedance of the $\mathrm{CPW}$ lines. Figure 5 displays the simulation results of the characteristic impedance for the CPW lines. In this simulation, the signal line is $35 \mu \mathrm{m}$ wide, $250 \mu \mathrm{m}$ long and $0.53 \mu \mathrm{m}$ thick. The space between the signal and ground lines is $3.3 \mu \mathrm{m}$. Table 1 summarizes characteristics of the CPW from the results in Figure 5. The results show that the CPW has a characteristic impedance of $50 \Omega$, and the value matches the impedance of the network analyzer, $50 \Omega$. Thereby, the incident electromagnetic wave in the switch has a small return loss.

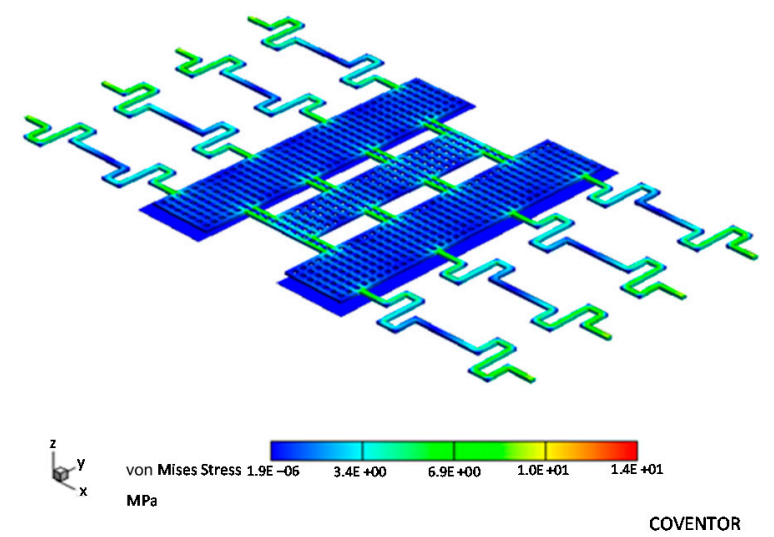

Figure 4. Stress distribution of the micromachined switch.

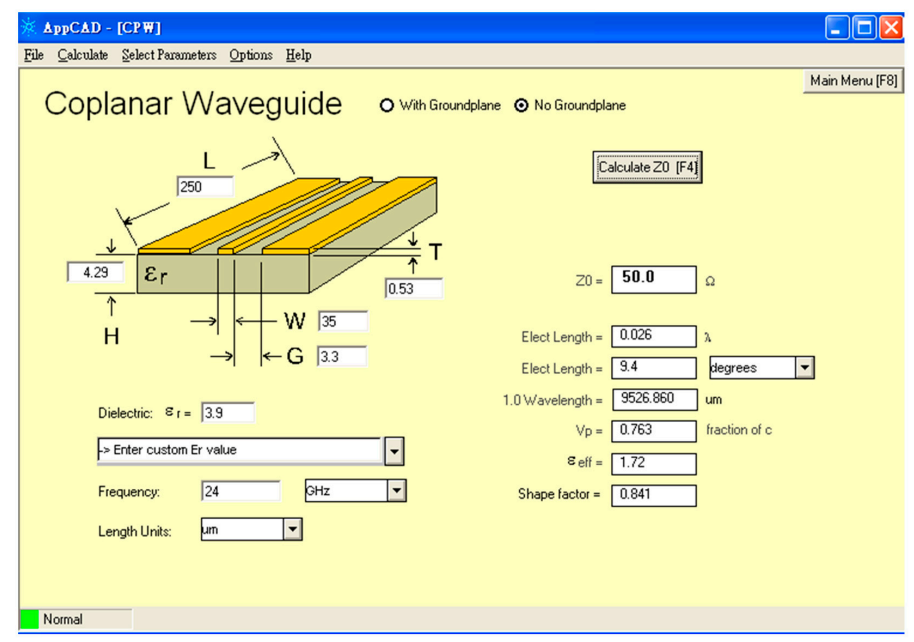

Figure 5. Simulation of characteristic impedance for the coplanar waveguide (CPW).

Table 1. Characteristics of the coplanar waveguide (CPW).

\begin{tabular}{cccc}
\hline Impedance & Wavelength & Effective Dielectric & Shape Factor \\
\hline $50 \Omega$ & $9752 \mu \mathrm{m}$ & 1.72 & 0.841 \\
\hline
\end{tabular}

The Agilent ADS (Agilent Technologies, Santa Clara, CA, USA) and the Ansoft Q3D extractor (Ansoft Technologies, New Delhi, DL, USA) were used to simulate the electrical properties of the 
switch. First, the Ansoft Q3D extractor [23] extracts the electrical parameters of the switch in accordance with the structure and dimensions as shown in Figure 1. The extracted results reveal that the membrane and springs have an inductance of $0.25 \mathrm{nH}$; the capacitance between the membrane and the signal line is $0.03 \mathrm{pF}$; the membrane and springs have a resistance of $2 \Omega$; the silicon substrate has a resistance of $250 \Omega$; the insulated capacitance under the CPW lines is $45 \mathrm{fF}$; the capacitance of silicon substrate $32 \mathrm{fF}$. Then, the electrical parameters are inputted into the Agilent ADS to evaluate the isolation and insertion loss of the switch. The simulation results of insertion loss for the switch are shown in Figure 6. The results depict that the insertion loss of the switch is $0.8 \mathrm{~dB}$ at $36 \mathrm{GHz}$. The simulation results of isolation for the switch are shown in Figure 7 . The results reveal that the switch has an isolation of $21 \mathrm{~dB}$ at $35 \mathrm{GHz}$. The inductors influence the capacitance and inductance between membrane and signal line, leading to change the isolation of the switch. Based on the simulation of Agilent ADS, we obtained that the switch with inductors increased the isolation of $6 \mathrm{~dB}$ than one without inductors. To enhance the isolation characteristic of the switch, the inductors are adopted. The working frequency of the RF switch is suitable for application in automotive radar system and communication satellite system.

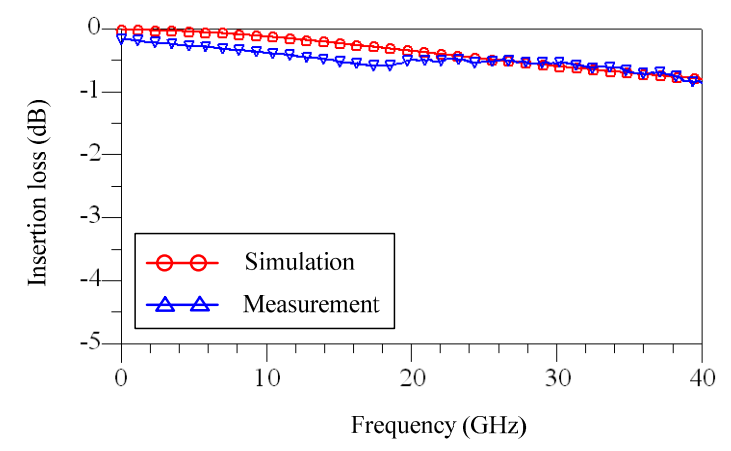

Figure 6. Simulation of insertion loss for the switch.

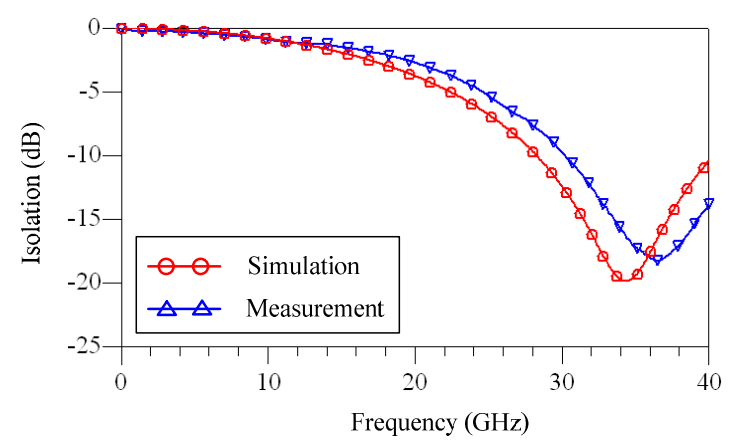

Figure 7. Simulation of isolation for the switch.

\section{Fabrication of the Micromachined Switch}

The micromachined switch was manufactured using the commercial $0.35 \mu \mathrm{m}$ CMOS process of the Taiwan Semiconductor Manufacturing Company (TSMC, Taipei, Taiwan). Figure 8 presents the fabrication flow of the micromachined switch. The $0.35 \mu \mathrm{m}$ CMOS process had four aluminum layers and one passivation layer. Thickness of all aluminum layers was about $1 \mu \mathrm{m}$. Material of the passivation layer was silicon nitride, and its thickness was about $1.5 \mu \mathrm{m}$. Figure 8a illustrates the cross-sectional view of the switch after completion of the CMOS process. A silicon dioxide layer under the membrane and springs was a sacrificial layer. To release the membrane and springs, the switch required a post-process to etch the sacrificial silicon dioxide layer [24,25]. Figure $8 b$ shows the cross-sectional view of the switch after the post-process. The sacrificial silicon dioxide layer was 
etched by buffer oxide etch (BOE) solution to obtain the suspended membrane and springs. The etching rate of the silicon oxide was about $150 \mathrm{~nm} / \mathrm{min}$. The wet etching needed to be timed for preventing to damage the aluminum structures. The etching time was about $24 \mathrm{~min}$. The anchors were made up of aluminum and stack-via layers. The material of via layers was tungsten. The springs and membrane material were aluminum. A scanning electron microscope (SEM) [26] was used to detect the profile of the micromachined switch. Figure 9 shows the SEM image of the micromachined switch after the post-process. Figure 10 displays the SEM image of the membrane in the switch. To prevent stiction problem and reduce etching time during the post-process, the membrane is designed with many etching holes as shown in Figure 10. Figure 11 shows an optical image of the micromachined switch to demonstrate the position of the CPW pads and actuation pads.

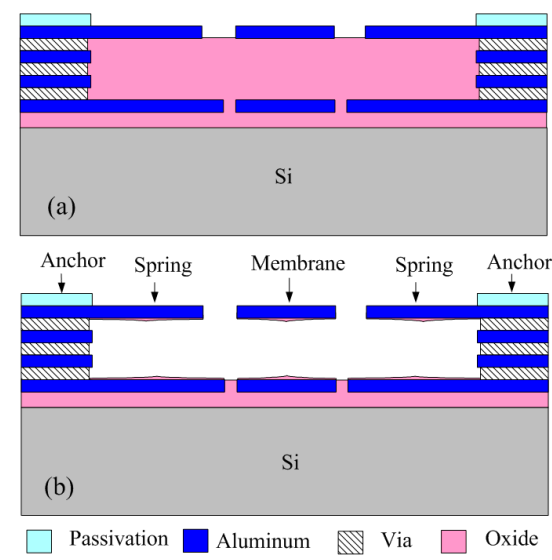

Figure 8. Fabrication flow of the switch: (a) after the complementary metal oxide semiconductor (CMOS) process; and (b) after the post-process.

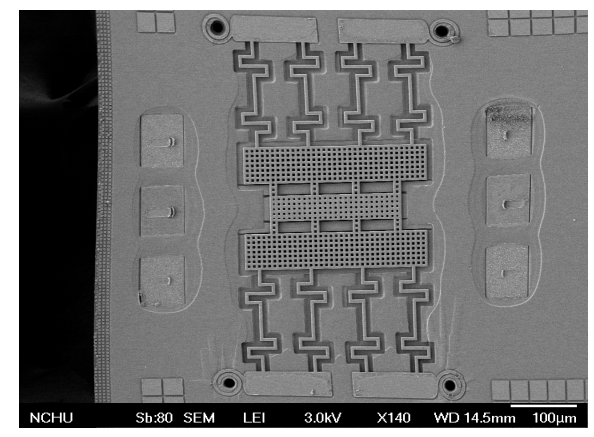

Figure 9. Scanning electron microscope (SEM) image of the micromachined switch.

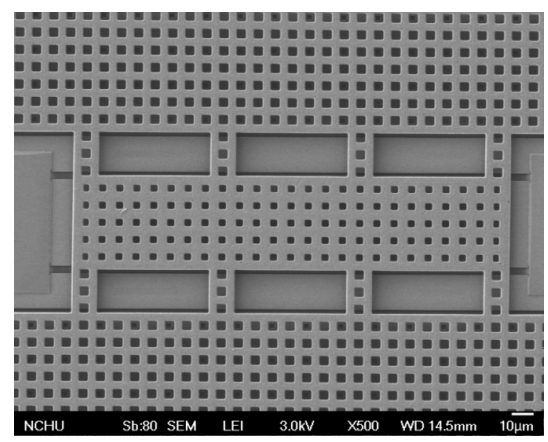

Figure 10. SEM image of the membrane. 


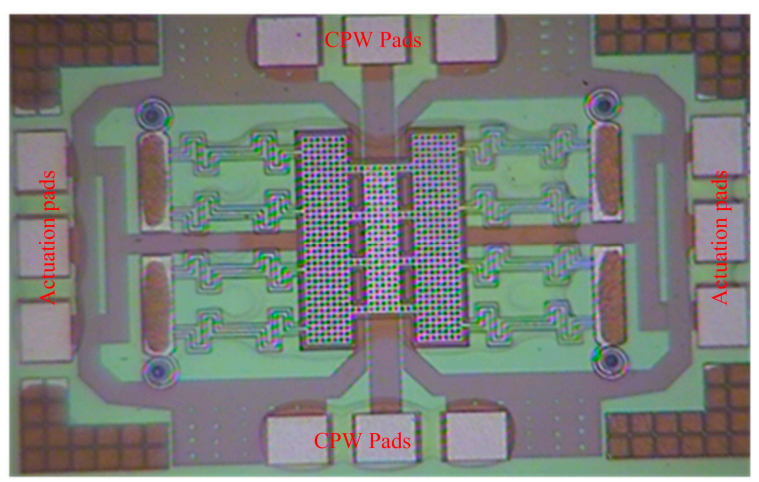

Figure 11. Optical image of the micromachined switch.

\section{Results}

A Cascade probe station and an Agilent 8510C network analyzer (Agilent Technologies) was employed to test the performances of the micromachined switch. When there was no applied voltage, the switch was in the "on" state. The scattering-parameters of the switch were measured in the frequency range $0-40 \mathrm{GHz}$ using the Agilent $8510 \mathrm{C}$ network analyzer. Figure 6 shows the measured results of insertion loss for the switch in the "on" state. The results showed that the insertion loss of the switch was $0.8 \mathrm{~dB}$ at $36 \mathrm{GHz}$. A comparison of the measurement and simulation results, the simulation results of insertion loss are in good agreement with the measurement results of insertion loss. Figure 12 shows the measured results of return loss for the switch. The results revealed that the switch had a return loss of $18 \mathrm{~dB}$ at $36 \mathrm{GHz}$.

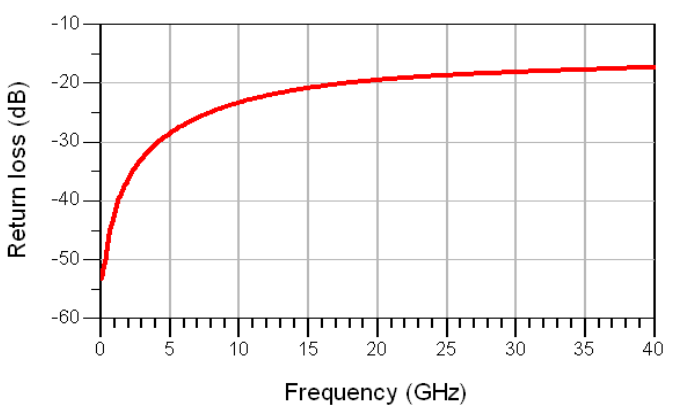

Figure 12. Return loss of the micromachined switch.

When applying an actuation voltage of $12 \mathrm{~V}$, the micromachined switch was in the "off" state. Figure 7 shows the measurement results of isolation for the switch in the "off" state. The measurement results revealed that the isolation of the switch was $19 \mathrm{~dB}$ at $36 \mathrm{GHz}$. As shown in Figure 7, the simulation results of isolation is $21 \mathrm{~dB}$ at $35 \mathrm{GHz}$. The difference between the measurement and simulation results of isolation is $2 \mathrm{~dB}$ at resonance frequency. A life-testing for the micromachined switch was measured. The tested results showed that the switch was still well by way of the cycle-testing of 2.5 million times.

The performances of RF MEMS switches [4-10] are summarized in Table 2. Wang et al. [4] manufactured a RF MEMS switch on the SOG substrate. The insertion loss of the switch was $0.77 \mathrm{~dB}$ at $6 \mathrm{GHz}$, and the isolation of the switch was $53 \mathrm{~dB}$ at $6 \mathrm{GHz}$. The switch has a pull-in voltage of $15 \mathrm{~V}$. Park et al. [9] proposed a RF MEMS capacitive shunt switch. The switch was actuated by electrostatic force. The pull-in voltage of the RF switch was $25 \mathrm{~V}$. The RF switch had an insertion loss of $0.29 \mathrm{~dB}$ at $24 \mathrm{GHz}$ and an isolation of $30.1 \mathrm{~dB}$ at $24 \mathrm{GHz}$. Comparing to Wang et al. [4] and Park et al. [9], the pull-in voltage $(12 \mathrm{~V})$ of this work is lower than that of Wang et al. [4] Park et al. [9]. The springs of the RF switch in this work is designed as S-shape, so the stiffness of springs reduces, leading to 
decrease the pull-in voltage. Giffney et al. [7] presented a piezoelectrically actuated capacitive RF MEMS switch. The switch was actuated by a lead zirconate titanate thin film [27]. The insertion loss of the switch was $0.7 \mathrm{~dB}$ at $14 \mathrm{GHz}$, and its isolation was $10 \mathrm{~dB}$ at $14 \mathrm{GHz}$. The pull-in voltage of the switch was $22.4 \mathrm{~V}$. The switch is difficult to integrate with circuitry on-a-chip because the piezoelectric material is not compatible with the commercial CMOS process. The isolation of this work exceeds that of Giffney et al. [7], because the capacitance variation of the switch in this work is high during switching. Yang et al. [8] proposed a RF MEMS capacitive switch with low sensitivity to both in-plane stress and stress gradients. The RF switch had a pull-in voltage of about $40 \mathrm{~V}$. The insertion loss of the switch was about $1 \mathrm{~dB}$ at $20 \mathrm{GHz}$, and the isolation of the switch was about $12 \mathrm{~dB}$ at $20 \mathrm{GHz}$. The pull-in voltage of this work exceeds that of Yang et al. [8], because the stiffness of the springs in this work is lower. The insertion loss and isolation of this work also exceed that of Yang et al. [8]. Zheng et al. [10] fabricated an RF MEMS membrane switch on a GaAs substrate using the surface micromachining process. The pull-in voltage of the RF switch was $17 \mathrm{~V}$. The RF switch had an isolation of $42 \mathrm{~dB}$ at $24.5 \mathrm{GHz}$ and an insertion of $0.25 \mathrm{~dB}$ at $25.6 \mathrm{GHz}$. The insertion loss and isolation of Zheng et al. [10] exceed that of this work, because GaAs substrate has excellent electrical property. But silicon substrate is lower cost than GaAs substrate.

Table 2. Performances of radio frequency (RF) microelectromechanical system (MEMS) switches.

\begin{tabular}{cccc}
\hline Authors & Insertion Loss & Isolation & Pull-In Voltage (V) \\
\hline Wang et al. [4] & $0.77 \mathrm{~dB}$ at $6 \mathrm{GHz}$ & $53 \mathrm{~dB}$ at $6 \mathrm{GHz}$ & 15 \\
Angira et al. [5] & $0.11 \mathrm{~dB}$ at $25 \mathrm{GHz}$ & $52 \mathrm{~dB}$ at $10 \mathrm{GHz}$ & 12.75 \\
Giffney et al. [7] & $0.7 \mathrm{~dB}$ at $14 \mathrm{GHz}$ & $10 \mathrm{~dB}$ at $14 \mathrm{GHz}$ & 22.4 \\
Yang et al. [8] & $1 \mathrm{~dB}$ at $20 \mathrm{GHz}$ & $12 \mathrm{~dB}$ at $20 \mathrm{GHz}$ & 40 \\
Park et al. [9] & $0.29 \mathrm{~dB}$ at $24 \mathrm{GHz}$ & $30.1 \mathrm{~dB}$ at $24 \mathrm{GHz}$ & 25 \\
Zheng et al. [10] & $0.25 \mathrm{~dB}$ at $25.6 \mathrm{GHz}$ & $42 \mathrm{~dB}$ at $24.5 \mathrm{GHz}$ & 17 \\
This work & $0.8 \mathrm{~dB}$ at $36 \mathrm{GHz}$ & $19 \mathrm{~dB}$ at $36 \mathrm{GHz}$ & 12 \\
\hline
\end{tabular}

\section{Conclusions}

A micromachined RF capacitive switch has been manufactured using the CMOS-MEMS technology. The post-process needed only one wet etching of BOE to etch the sacrificial silicon oxide layer, and to release the suspended membrane and springs of the switch. The micromachined switch has a potential of mass-production owing to its post-process is compatible with the commercial CMOS process. The advantages of the switch included easy post-process, low actuation voltage and low cost. The pull-in voltage of the switch simulated by the FEM software CoventorWare was $12.5 \mathrm{~V}$. The experimental results revealed that the pull-in voltage of the switch was $12 \mathrm{~V}$, which it was in good agreement with the simulation result. The measurement results depicted that the micromachined switch had an insertion loss of $0.8 \mathrm{~dB}$ at $36 \mathrm{GHz}$, and the value was in good agreement with the simulation value. The measured isolation of the switch was $19 \mathrm{~dB}$ at $36 \mathrm{GHz}$.

Acknowledgments: The authors would like to thank National Center for High-performance Computing (NCHC) for chip simulation; National Chip Implementation Center (CIC) for chip fabrication and the Ministry of Science and Technology of the Republic of China for financially supporting this research under Contract No MOST 104-2221-E-005-029-MY2.

Author Contributions: Cheng-Yang Lin carried out the design and fabrication of the micromachined RF capacitive switch and measured its characterization. Cheng-Chih Hsu simulated the performances of the micromachined RF capacitive switch. Ching-Liang Dai supervised the work of Cheng-Yang Lin and wrote the paper. All authors read and approved the final manuscript.

Conflicts of Interest: The authors declare no conflict of interest. 


\section{References}

1. Goldsmith, C.; Randall, J.; Eshelman, S.; Lin, T.H.; Denniston, D.; Chen, S.; Norvell, B. Characteristics of micromachined switches at microwave frequencies. In Proceedings of the IEEE MTT-S International Microwave Symposium Digest, San Francisco, CA, USA, 17-21 June 1996; pp. 1141-1144.

2. Hah, D.; Yoon, E.; Hong, S. A low voltage actuated microelectromechanical switch for RF application. Jpn. J. Appl. Phys. 2001, 40, 2721-2724. [CrossRef]

3. Schiavone, G.; Desmulliez, M.P.Y.; Walton, A.J. Integrated magnetic MEMS relays: Status of the technology. Micromachines 2014, 5, 622-653. [CrossRef]

4. Wang, L.F.; Han, L.; Tang, J.Y.; Huang, Q.A. Laterally-actuated inside-driven RF MEMS switches fabricated by a SOG process. J. Micromech. Microeng. 2015, 25, 065007. [CrossRef]

5. Angira, M.; Rangra, K. Design and investigation of a low insertion loss, broadband, enhanced self and hold down power RF-MEMS switch. Microsystem Technol. 2015, 21, 1173-1178. [CrossRef]

6. Gao, Y.F.; You, Z.; Zhao, J.H. Electrostatic comb-drive actuator for MEMS relays/switches with double-tilt comb fingers and tilted parallelogram beams. J. Micromech. Microeng. 2015, 25, 045003. [CrossRef]

7. Giffney, T.; Aw, K.; Yu, M.; Gao, W.; Zhang, H.X. Design and modeling of a continuously variable piezoelectric RF MEMS switch. Microsystem Technol. 2015, 21, 1293-1300. [CrossRef]

8. Yang, H.H.; Zareie, H.; Rebeiz, G.M. A high power stress-gradient resilient RF MEMS capacitive switch. J. Microelecromech. Syst. 2015, 24, 599-607. [CrossRef]

9. Park, J.; Shim, E.S.; Choi, W.; Kim, Y.; Kwon, Y.; Cho, D.I. A non-contact-type RF MEMS switch for 24-GHz radar applications. J. Microelectromech. Syst. 2009, 18, 163-173. [CrossRef]

10. Zheng, W.B.; Huang, Q.A.; Liao, X.P.; Li, F.X. RF MEMS membrane switches on GaAs subtrates for $x$-band applications. J. Microelectromech. Syst. 2005, 15, 464-471. [CrossRef]

11. Dai, C.L.; Kao, P.H.; Tai, Y.W.; Wu, C.C. Micro FET pressure sensor manufactured using CMOS-MEMS technique. Microelectron. J. 2008, 39, 744-749. [CrossRef]

12. Uranga, A.; Verd, J.; Barniol, N. CMOS-MEMS resonators: From devices to applications. Microelecrtron. Eng. 2015, 132, 58-73. [CrossRef]

13. Li, M.H.; Chen, C.Y.; Li, C.S.; Chin, C.H.; Li, S.S. A monolithic CMOS-MEMS oscillator based on an ultra-low-power ovenized micromechanical resonator. J. Microelectromech. Syst. 2015, 24, 360-372. [CrossRef]

14. Yang, M.Z.; Dai, C.L.; Wu, C.C. A zinc oxide nanorod ammonia microsensor integrated with a readout circuit on-a-chip. Sensors 2011, 11, 11112-11121. [CrossRef] [PubMed]

15. Dai, C.L.; Chen, Y.C.; Wu, C.C.; Kuo, C.F. Cobalt oxide nanosheet and CNT micro carbon monoxide sensor integrated with readout circuit on chip. Sensors 2010, 10, 1753-1764. [CrossRef] [PubMed]

16. Xue, Q.N.; Bian, C.; Tong, J.H.; Sun, J.Z.; Zhang, H.; Xia, S.H. CMOS and MEMS based micro hemoglobin-A1c biosensors fabricated by various antibody immobilization methods. Sens. Actuators A Phys. 2011, 169, 282-287. [CrossRef]

17. Yang, M.Z.; Dai, C.L.; Shih, P.J.; Chen, Y.C. Cobalt oxide nanosheet humidity sensor integrated with circuit on chip. Microelectron. Eng. 2011, 88, 1742-1744. [CrossRef]

18. Marigó, E.; Muñoz-Gamarra, J.L.; Vidal, G.; Giner, J.; Torres, F.; Uranga, A.; Barniol, N. Cross coupled beams CMOS-MEMS resonator for VHF range with enhanced electrostatic detection. Microelectron. Eng. 2011, 88, 2325-2329. [CrossRef]

19. Yang, M.Z.; Dai, C.L.; Lin, W.Y. Fabrication and characterization of polyaniline/PVA humidity microsensors. Sensors 2011, 11, 8143-8151. [CrossRef] [PubMed]

20. Dai, C.L.; Chiou, J.H.; Lu, M.S.C. A maskless post-CMOS bulk micromachining process and its application. J. Micromech. Microeng. 2005, 15, 2366-2371. [CrossRef]

21. Senturia, S.D. Microsystem Design; Kluwer Academic: Norwell, MA, USA, 2001.

22. Dai, C.L.; Chang, Y.M. A resonant method for determining mechanical properties of $\mathrm{Si}_{3} \mathrm{~N}_{4}$ and $\mathrm{SiO}_{2}$ thin films. Mater. Lett. 2007, 61, 3089-3092. [CrossRef]

23. Dai, C.L.; Chen, Y.L. Modeling and manufacturing of micromechanical RF switch with inductors. Sensors 2007, 7, 2660-2670. [CrossRef]

24. Chen, W.C.; Fang, W.; Li, S.S. A generalized CMOS-MEMS platform for micromechanical resonators monolithically integrated with circuits. J. Micromech. Microeng. 2011, 21, 065012. [CrossRef] 
25. Dai, C.L.; Hsu, H.M.; Tsai, M.C.; Hsieh, M.M.; Chang, M.W. Modeling and fabrication of a microelectromechanical microwave switch. Microelectron. J. 2007, 38, 519-524. [CrossRef]

26. Lee, C.Y.; Chang, C.; Shih, W.P.; Dai, C.L. Wet etching rates of InGaZnO for the fabrication of transparent thin-film transistors on plastic substrates. Thin Solid Film. 2010, 518, 3992-3998. [CrossRef]

27. Dai, C.L.; Xiao, F.Y.; Lee, C.Y.; Cheng, Y.C.; Chang, P.Z.; Chang, S.H. Thermal effects in PZT: Diffusion of titanium and recrystallization of platinum. Mater. Sci. Eng. A 2004, 384, 57-63. [CrossRef]

(C) 2015 by the authors; licensee MDPI, Basel, Switzerland. This article is an open access article distributed under the terms and conditions of the Creative Commons by Attribution (CC-BY) license (http:/ / creativecommons.org/licenses/by/4.0/). 